Int. J. Dev. Biol. 64: 41-44 (2020)

https://doi.org/10.1387/ijdb.200147sg

\title{
Leela Mulherkar and the teaching of developmental biology
}

\author{
SURENDRA GHASKADBI* \\ Developmental Biology Group, MACS-Agharkar Research Institute, Pune, India
}

\begin{abstract}
The formal teaching of developmental biology in India began in the late nineteen-fifties at the Department of Zoology of the University of Poona. This was due to the efforts of Leela Mulherkar, who on her return from C.H. Waddington's laboratory in Edinburgh, took up the teaching of embryology at the Master's level. Mulherkar began using locally available material to teach how animals develop. They included the embryos of chicken, frog, garden lizard and molluscs, as well as organisms such as hydra and sponges. Her teaching was supported by an active research laboratory that used all these systems to address a variety of questions in embryology and teratology. She used chick embryo explants cultured in vitro extensively in her work. Teaching and research in embryology at the master's and doctoral levels at Poona University subsequently led, in 1977, to the establishment of the Indian Society of Developmental Biologists (InSDB), which is among the most active scientific societies in India.
\end{abstract}

KEY WORDS: teaching, Waddington, embryology, InSDB

In September 1954, while teaching Zoology at Sir Parshurambhau College in Pune, Leela Mulherkar, who was then in her late thirties, won a modified overseas fellowship from the Government of India to go to Edinburgh in the UK to pursue a Doctorate. She got the opportunity to work in arguably one of the best places for doing organismal biology at the time, that of $\mathrm{C}$. H. Waddington. Conrad Hal Waddington was already a legend due to his pioneering contributions to biology in general and embryology in particular. Waddington had extended the scope of Spemann and Mangold's discovery of the amphibian organizer (Spemann and Mangold 2001) to the chick embryo, by showing that the anterior one third of the primitive streak exhibits organizer activity (Waddington 1932). Mulherkar's doctoral work, which she carried out between September 1954 and December 1956, was to find out if regions adjacent to the primitive streak too possess neural inductive capacity. She planned and successfully carried out a series of grafting experiments in cultured chick embryo explants (Mulherkar 1956, 1958). The experiments were technically challenging. They involved cutting out, with tungsten needles, pieces of about 0.3 square $\mathrm{mm}$ from areas around the streak, grafting them at appropriate places on host explants, and following the development of the host in New's culture medium (New 1955). The length of the entire primitive streak was about 1.7 to $2.1 \mathrm{~mm}$ (Mulherkar 1958), which gives an idea of the skill involved. Mulherkar performed over 300 grafts and analysed about $90 \%$ of the explants histologically. Her major discovery was that in addition to the anterior part of the streak, tiny regions of about $0.3 \mathrm{~mm}$ on the anterior and lateral sides also possess inducing activity. Probably the most significant achievement of her doctoral work was that it allowed her to predict the existence of antero-posterior and medio-lateral gradients of inducting capacity in the region adjoining the streak. This could be clearly seen in the quantitative analysis presented in the paper (Fig. 1). Further, depending on the kind of tissue induced by grafts from various locations, Mulherkar could ask the interesting question: Are neural and mesoderm inducing signals different?

The chick embryo was to remain Mulherkar's favourite system. Shortly after returning to India (Fig. 2), she joined the Department of Zoology of University of Poona (now Savitribai Phule Pune University) and established an embryology laboratory. She designed a course in embryology which Master's students could opt for as a specialization in their second year. The laboratory part of the course was designed in such a manner that locally available material could be used. Chick, frog, toad, lizard and snail embryos were used. She was an unusual teacher for the time: she used the latest issues of Journal of Embryology and Experimental Morphology (now Development) and Wilhelm Roux' Archiv für Entwicklungsmechanik der Organismen (later Roux's Archives of Developmental Biology and now Development, Genes and Evolution) in her teaching.

She continued her work on embryonic induction in the chick embryo with a number of students (a few of these are seen in Fig. 3). Her lab employed several state-of-the-art techniques in embryology.

Abbreviations used in this paper: InSDB, Indian Society of Developmental Biologists .

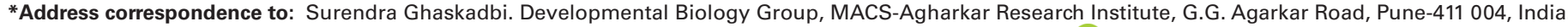
Phone: +91 20 25325063. Fax: +91 20 25651542. Email: smghaskadbi@aripune.org ; ghaskadbi@gmail.com - (iD https://orcid.org/0000-0002-7367-2049
} 


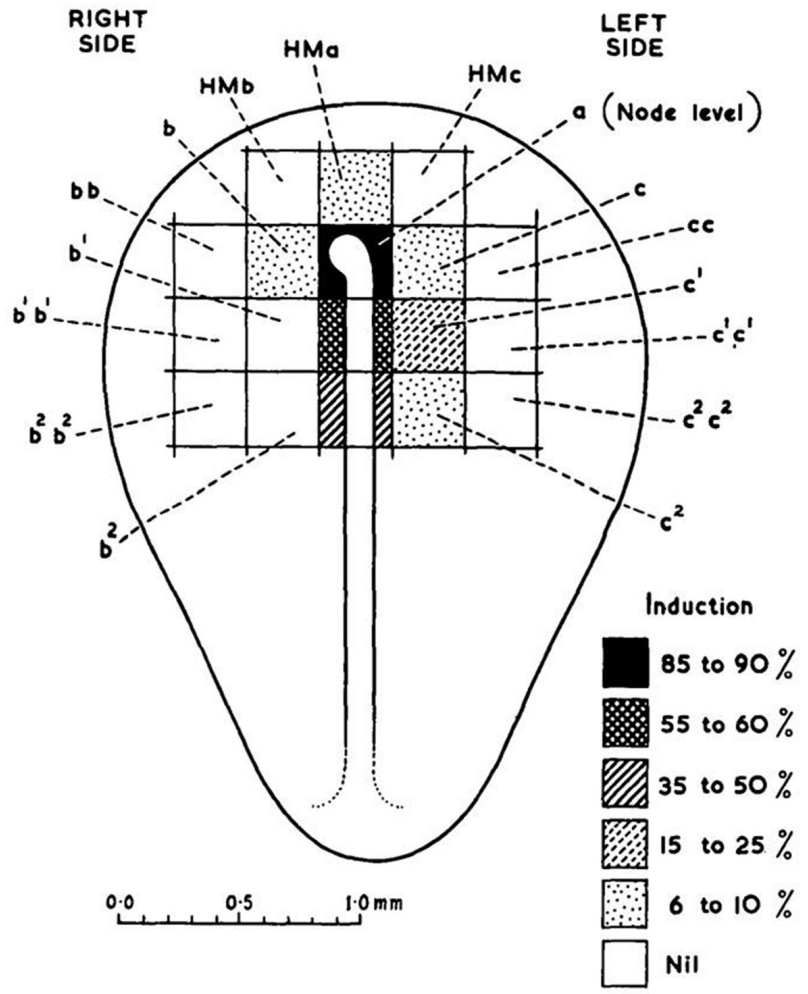

TEXT-FIG. 3. Graphic representation of the extent of the organization centre.

Fig. 1 (above). Graphic representation of the extent of the organization centre. Reproduced with permission from Mulherkar (1958). A definite streak stage chick embryo (HH stage 4) with anterior end towards the top. Hensen's node is the bulged structure in the darkest square. a, a 1, a 2 stand for cuts in the streak successively hind wards, b, b 1, b 2 for cuts on the left and c, c 1, c 2 for cuts on the right of the primitive streak. $b b, b 1 b 1, b 2$ b 2 and cc, c 1 c 1, c 2 c 2 are squares still farther away.
In order to better understand the self-differentiating and inductive capacity of the Hensen's node in a neutral environment (i.e. under circumstances in which there were believed to be no direct effects of any inducing factors), an intra-coelomic grafting technique was employed (Viswanath and Mulherkar 1972). Hensen's node tissue from a definitive chick primitive streak embryo (Hamburger Hamilton stage 4) was sandwiched between ectodermal pieces taken from antero-lateral sides of the node. After allowing the tissues to adhere to each other, the whole was grafted into the coeloms of host embryos of 2.5 days in ovo. These are challenging manipulations, as the host embryo needs to be kept intact inside the shell while carefully placing the sandwich graft into its coelom through a window made in the shell. After sealing the window, the host was allowed to develop for a further 12 to 14 days. At the end of the incubation the grafts inside the coelom were excised and processed for histology. The outcome clearly pointed to the self-differentiating and inducing capacity of Hensen's node tissue in a neutral environment. The study also allowed the authors to predict existence of separate inducing factors of ectodermal and mesodermal origin.

A standard approach of embryologists interested in the mechanisms of differentiation was to study the effects of a variety of exogenous agents - ions, chemicals and physical agents, etc. - on developing animal embryos. Not surprisingly, more often than not the upshot was that the embryo developed abnormally ("monster" was a common description). As a result, a substantial part of the knowledge of normal development came by studying the abnormal. This approach is still widely used, though the ways in which one can interfere with development have become more sophisticated and precise, due initially to availability of mutants and more recently because of the methods of molecular biology, especially recombinant DNA technology. There was another reason why a large number of scientists began to get involved at that time (the mid-to-late 1960s onwards) on trying to understand the origin of developmental abnormalities. Thalidomide, which had been marketed as a safe sleeping pill for pregnant women, turned out

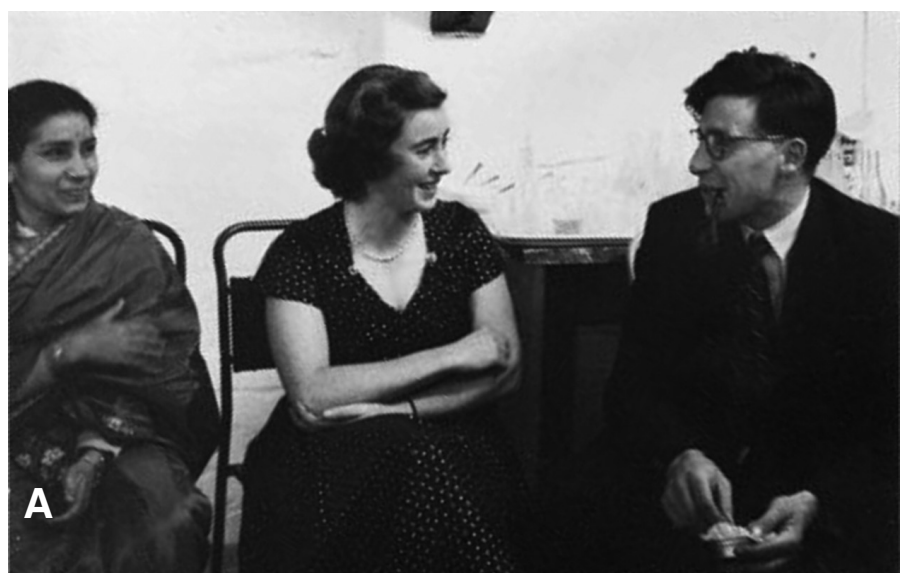

Fig 2. Mulherkar's Edinburgh connection. (A) Leela Mulherkar in Edinburgh in the mid-1950s. (LR) Leela Mulherkar, Gillian Currie and Bob Edwards (from album presented to Waddington by the Institute of Animal Genetics staff on his 50th birthday). (B) Waddington and Leela Mulherkar sometime in the late nineteen-fifties when the former visited the Department of Zoology, S.P. Pune University, Pune.

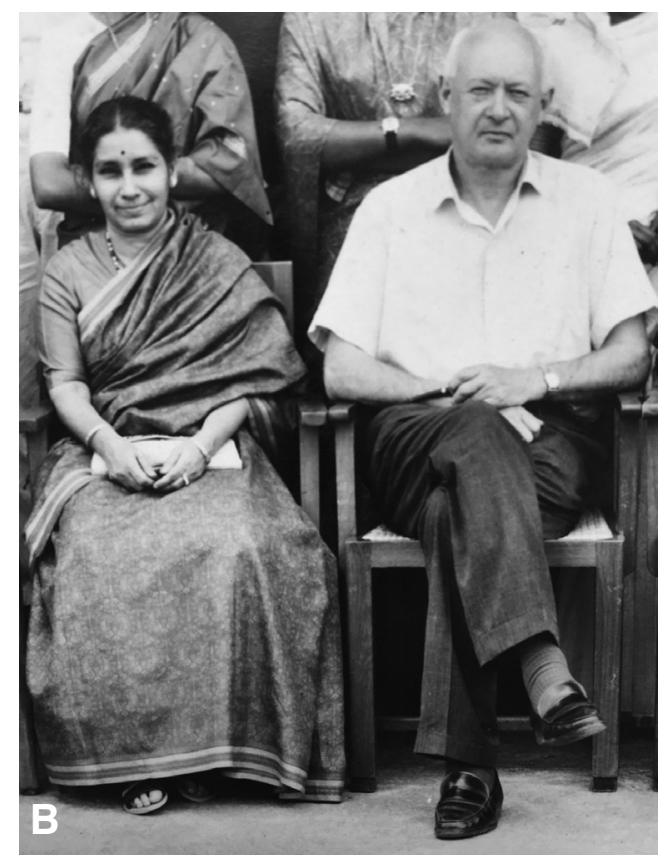


to cause severe limb malformations in the growing embryo. The tragedy, which struck in the late fifties and early sixties, brought the study and analysis of abnormal development to the forefront. Mulherkar's laboratory began looking at embryonic development with a view to understanding the teratogenic effects of chemical and physical agents. Some of her studies brought out the role of sufhydryl groups in interactions between cells during morphogenesis. Details of the work carried out at Pune University can be found elsewhere in this volume (Modak, 2020). Mulherkar's work with the chick embryo pointed towards gradients of signaling molecules during morphogenesis though she did not use these precise words. Some of her work led to deciphering mechanisms of action of several teratogens. Mulherkar pioneered the teaching of embryology in India by designing curricula using local materials. It is important that we continue this legacy as developmental biology cannot and should not be restricted to the so-called model systems.

Mulherkar was very dedicated to her work. In 1960s and 1970s it was not possible for a lady to work alone in the laboratory at late hours. Mulherkar carried her experimental set up consisting of developing frog embryos, chemicals, fixatives, pipettes and dissecting binoculars to her house on the university campus so that she could observe and harvest the embryos at defined time points throughout the night. She was a strict disciplinarian who was often harsh to her colleagues and students who seemed to be wasting their time. Not surprisingly, therefore, most were frightened of her. I have heard stories of some of her faculty colleagues and students running helter-skelter as she walked from her house to the Zoology department. The lush green campus of the University provided them with plenty of places to hide. Fortunately for me, when I joined her in early 1980 s as her last 'full time' doctoral student (she continued to mentor doctoral students afterwards jointly with Sohan Modak), she had mellowed down considerably. In fact many wondered how I came out unscathed after sharing an office and a writing table with her for over three years. She would even treat me to batata vada (a very popular Maharashtrian potato snack, which she herself loved) when we worked together late in the evening. She never allowed me to pay, which suited me fine with my meagre monthly fellowship of Rs. 600/- (less than 60 US dollars then). By some strange coincidence, when my father decided to buy a house in Pune in 1985, he ended up buying Mulherkar's flat on Prabhat Road, one of the most sought-after localities in Pune. Staying for the past 35 years in a house earlier owned by my mentor, who was in turn mentored by Waddington, has been and continues to be a humbling and sobering experience.

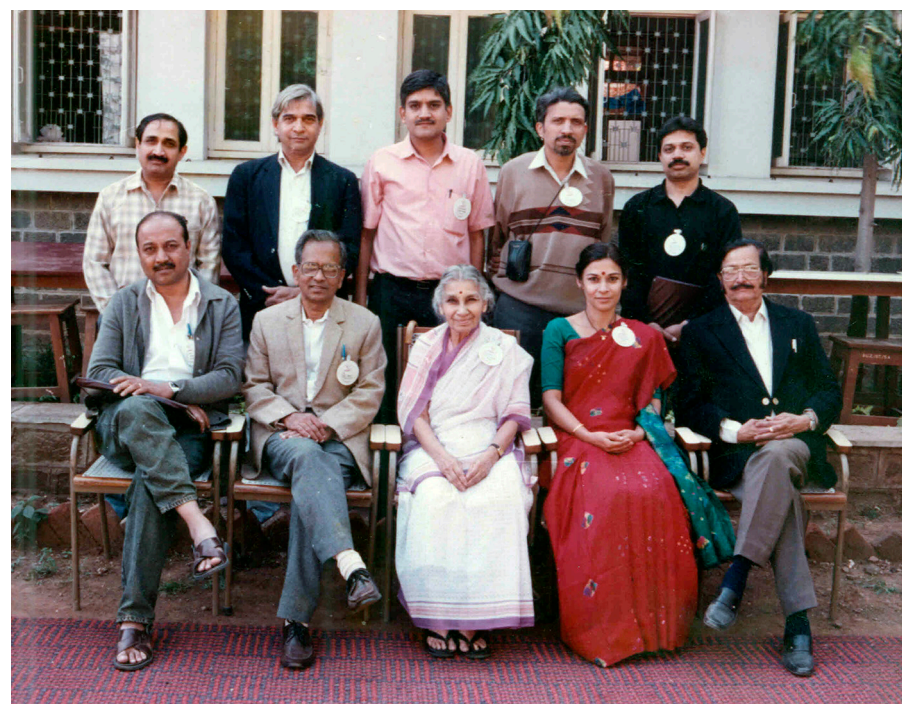

Fig 3. Mulherkar with some of her students during the International Symposium on Developmental Regulation at Savitribai Phule Pune University, Pune, India (December 1993). Sitting (L-R): M.Z. Khan, K.V. Rao, L. Mulherkar, M.S. Katdare and M.V. Joshi. Standing (L-R):R.R. Bhonde, S.P. Modak. S. Ghaskadbi, H.V. Ghate and S.K. Ghatpande.

\section{An inspirational role model}

\section{by Rita Mulherkar (rmulherkar@gmail.com)}

Leela Mulherkar Golay was my grandfather's youngest sister. She was my role model even as a child. When she had returned from Edinburgh in the late 1950s, my father offered to drive her to Pune from Mumbai. I was hardly 8 years old but I remember distinctly how passionately she spoke about her work, although I did not understand a word! I wanted to be a 'scientist' like her at that young age. As fate would have it, I took zoology as my principal subject for my B.Sc. and later joined the Zoology Department at Pune University where she was Head.

During the second year of my M.Sc. programme, I took Embryology as my major subject. During the first week we were shown a film where a young Dr. Mulherkar demonstrated ex vivo whole chick embryo culture using New's glass ring technique. It was fascinating to watch the film. Unfortunately, it could not be found in the Zoology Department later when I tried to find it. Some of her lectures on chick embryology are still fresh in my mind. Besides being a good teacher, she was a strict disciplinarian and everyone was terrified of her, including me! Once she made a peon go on leave because he was not wearing a proper uniform.

Dr. Mulherkar was very fond of Marathi plays and would always invite me to go with her and Mr. Vasantrao Golay, her husband. Their seats at the Bal Gandharva auditorium were always reserved in the first row. Once, I think it was for the play Swami, we had seats on the second row and she was terribly unhappy! For me it was such a treat to sit in the front rows as, when I went with friends, we would sit at the very back in the cheapest seats which we could afford as students.

In early 2005, when her health was failing, she received a letter from an American scientist saying that he had received an award and that he had dedicated his award lecture to her. This was such an honour. Unfortunately, I never got to see the letter and could not find out the name of the scientist. I only heard about it much later.

Leela Mulherkar was a unique person who was kind and yet strict. She was an excellent teacher. Her students are spread across the globe, some holding very high positions. As a woman, what she achieved in the early 1950 s is indeed very creditable. She is a true 'Lilavati's daughter' and an inspiration for all women. 


\section{S. Ghaskadbi}

\section{References}

MODAK, S.P. (2020). Cell population growth regulates dorsalization and caudalization during chick morphogenesis and programmed cell death in lens fibres. Int. J. Dev. Biol. 64: 45-57.

MULHERKAR, L. (1956). Studies in the process of determination in the chick embryo. $\mathrm{Ph}$. D. thesis, Institute of Animal Genetics, University of Edinburgh.

MULHERKAR, L. (1958). Inductions by regions lateral to the streak in chick embryo. J Embryol Exp Morphol 6: 1-14.
NEW, D.A.T. (1955). A new technique for the cultivation of chick embryo in vitro. $J$ Embryol Exp Morphol 3: 326-331.

SPEMANN, H., MANGOLD, K. (2001) Induction of embryonic primordia by implantation of organizers from a different species 1923. Int J Dev Biol 43: 13-38.

VISWANATH, J.R., MULHERKAR, L. (1972). Studies on self-differentiating and induction capacities of Hensen's node using intracoelomic grafting technique. $J$ Embryol Exp Morphol 28: 547-558.

WADDINGTON, C.H. (1932). Experiments on the development of chick and duck embryos, cultivated in vitro. Phil Tran R Soc Lond 221: 179-230.
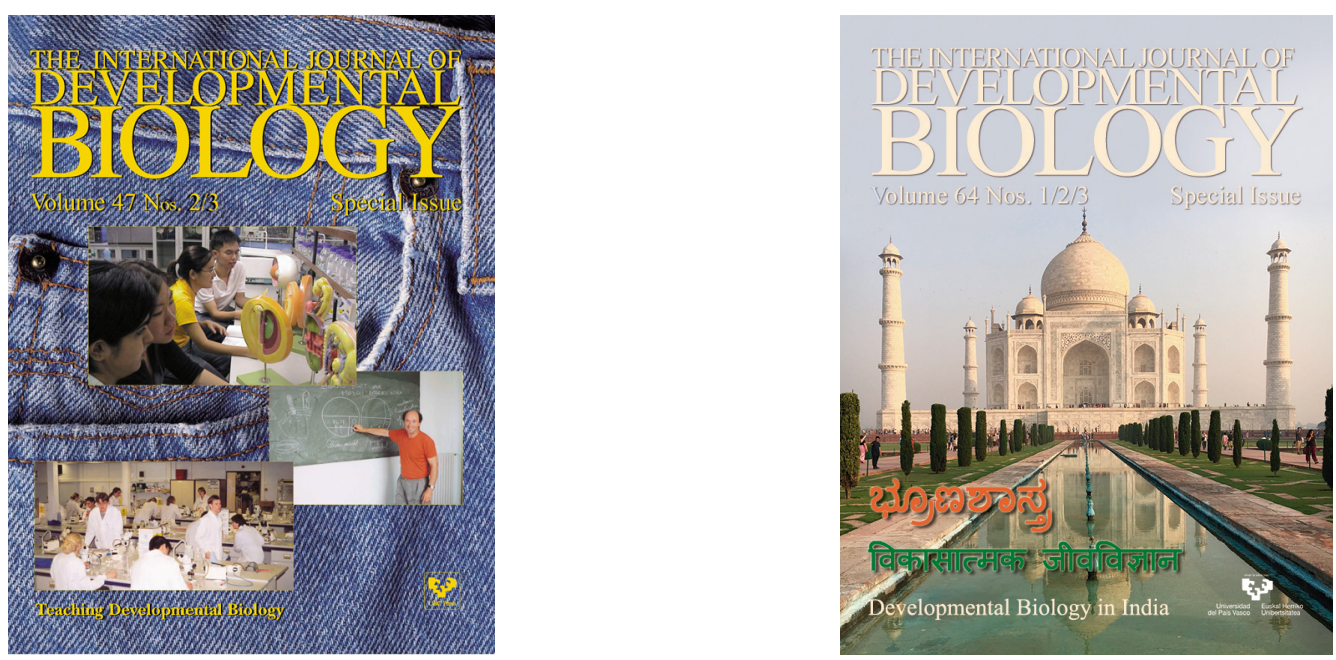